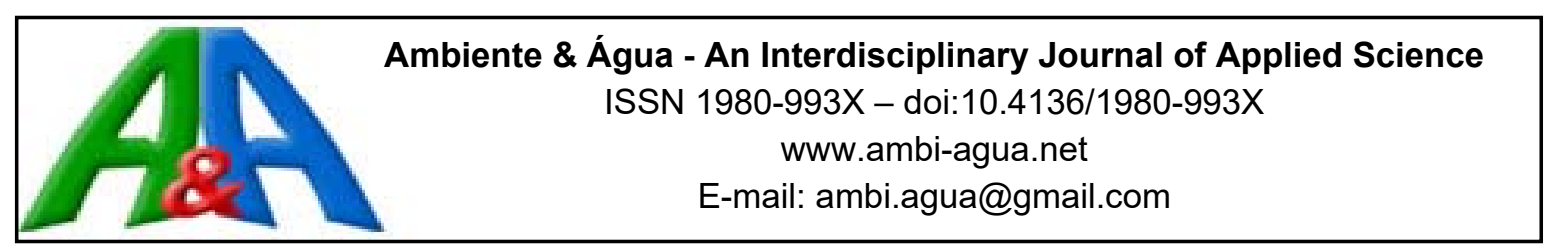

\title{
Zoneamento da bacia hidrográfica do rio Moju (Pará): usos da água e sua relação com as formas de uso e cobertura do solo
}

\author{
doi:10.4136/ambi-agua.2069
}

Received: 21 Dec. 2016; Accepted: 08 May 2017

\author{
Susane Cristini Gomes Ferreira; Aline Maria Meiguins de Lima*; \\ José Augusto Martins Corrêa \\ Universidade Federal do Pará (UFPA), Belém, PA, Brasil \\ Programa de Pós-Graduação em Ciências Ambientais \\ *Autor correspondente: e-mail: ameiguins@ufpa.br, \\ susane_cristini@hotmail.com,jamc@ufpa.br
}

\section{RESUMO}

A bacia do rio Moju apresenta diferentes padrões de usos da terra decorrentes de um histórico de expansão do setor agrícola e extrativista no estado. Está inserida na área de projetos desenvolvimentistas da região, com ênfase para a cadeia produtiva do dendê. No presente trabalho, realizou-se um zoneamento da bacia do rio Moju evidenciando a interconexão entre os principais usos e cobertura da terra e os usos da água, demonstrando as pressões sobre os recursos naturais que a bacia está sofrendo. O zoneamento é o produto resultante da associação entre o mapeamento de uso e cobertura da terra e as categorias de usuários da água dos municípios componentes da bacia. Os resultados demonstraram que a maior parcela de usos outorgados tem finalidade industrial, sendo a captação subterrânea massivamente superior a superficial, onde o principal outorgado é a agroindústria do dendê. Somente um pequeno número de habitantes são atendidos pela distribuição de água e ocorrem grandes perdas no sistema de distribuição. A sub-bacia Alto Moju sofre alta pressão sobre os seus recursos naturais. Nota-se que a bacia como um todo ainda possui a maior parte de seu território com cobertura florestal, entretanto a pastagem e a vegetação secundária ocupam áreas expressivas. Em geral, percebe-se que o maior desafio está em alinhar o gerenciamento dos recursos hídricos com uma gestão eficiente de uso do solo.

Palavras-chave: agroindústria do dendê, Amazônia, usuários de água.

\section{Zoning of the hydrographic basin of Moju river (Pará): Water use and its relation with the forms of land cover and land use}

\begin{abstract}
The Moju River Basin presents different patterns of land use resulting from a historic expansion of the agricultural and extractive sector in the state. It is embedded in the area of developmental projects in the region, with emphasis on the palm oil productive chain. In the present work, a zoning of the Moju River Basin has been carried out, evidencing the interconnection between the land use and land cover and the water use, showing the pressures on the natural resources that the basin is undertaking. The zoning is a product resulting from the association between land use and land cover mapping, and the categories of water users of
\end{abstract}


the municipalities that compound the basin. The results showed that the greatest water user grant has industrial purpose, with underground extraction massively than the superficial, where the palm oil industry has the highest water use grant. Only a small number of inhabitants are served by water distribution and there are high rates of loss in the distribution system. The Alto Moju sub-basin suffers high pressure on its natural resources. We noticed that the basin as a whole has most of its territory covered by forest, although pasture and secondary vegetation are also expressive. In general, we observed that the biggest challenge is to align the management of water resources and efficient land use.

Keywords: Amazon, palm oil industry, water users.

\section{INTRODUÇÃO}

A gestão inadequada das bacias hidrográficas tem ocasionado problemas sérios de disponibilidade de água, tanto em níveis quantitativos quanto qualitativos à população, configurando situações de crise hídrica. Enfrentar os sérios problemas de acesso à água, que atingem mais severamente a população de baixa renda dos pequenos municípios e das periferias dos grandes centros urbanos, é fundamental para avançar no caminho do crescimento ambientalmente responsável (ANA, 2010). Segundo os dados da Pesquisa Nacional sobre Saneamento Básico (IBGE, 2008), o número de domicílios abastecidos por rede geral de água na Região Norte subiu irrisoriamente de 44,3\% em 2000, para 45,3\% em 2008.

O planejamento das bacias hidrográficas vem se alterando conceitualmente, primeiro com o enfoque no manejo de águas, depois com uma concepção da bacia como a conjunção de fatores ambientais e, mais recentemente, com uma visão de planejamento ambiental integrado (Rodriguez et al., 2011). A Lei das Águas (Brasil, 1997) prevê em suas diretrizes a articulação da gestão hídrica com a gestão ambiental e com a gestão de uso do solo, por entender que não há possibilidade de uma gestão eficiente sem que se leve em consideração a interligação dos recursos naturais. Dentro desse contexto, é de grande importância o entendimento da bacia hidrográfica como unidade de gestão (Swarowsky et al., 2011).

No mais, a proposição de gestão ambiental em bacias hidrográficas surge como um importante exemplo do desenvolvimento de instrumento metodológico e prático, para a prática da relação sociedade e natureza, dentro de uma perspectiva inter e multidisciplinar, rompendo com os valores positivistas (Bordalo e Costa, 2012). As bacias hidrográficas da Amazônia possuem rios extensos, com grandes volumes hídricos além de estarem situadas na Zona Climática Intertropical, com índices de pluviosidade média anual em torno de $1800 \mathrm{~mm}$ (Bordalo et al., 2012). Contudo, ainda como característica comum, apresentam ineficiência no sistema de gestão dos seus recursos hídricos e precariedade na efetivação de políticas públicas tanto no enfoque ambiental da preservação e manutenção de seus mananciais quanto no social, no que se refere a qualidade de vida de sua população.

Nesse contexto amazônico está inserida a bacia do rio Moju. Na perspectiva socioeconômica, a bacia do rio Moju faz parte do quadro delineado por Becker (2009) para o nordeste paraense, onde são observadas as mudanças decorrentes da abertura da rodovia BelémBrasília e de outras estradas construídas para o acesso a essa rodovia, que ocasionou uma maior mobilidade de pessoas e mercadorias a partir da década de 1960. Essa região configura-se como uma das mais antigas áreas de ocupação da Amazônia, sendo a iniciante nos grandes projetos econômicos do estado (Bordalo et al., 2012; Ferreira et al., 2016).

O panorama atual traz para esse espaço o cultivo do dendê, que entre 2004 e 2010 dobrou sua área plantada. O óleo do dendê tem diversas aplicações, sendo utilizado em produtos alimentares e para fins industriais, este último predominantemente para biodiesel, o que o tornou ainda mais valorizado frente aos projetos desenvolvimentistas como a Política Nacional 
de Produção e Uso de Biodiesel (PNPB) com finalidades de consolidar o Polo de Biodiesel do Pará (Lees et al., 2015; Villela et al., 2014; USDA, 2010).

A expansão do dendê no nordeste paraense ocasionou problemas, tais como: concentração fundiária, conflitos no campo, risco ambiental sobre os corpos d'água por conta da abertura de estradas e da intensidade de herbicidas, fungicidas, bem como de adubo (Nahum e Santos, 2013). Nesse sentido, o presente trabalho tem como objetivo realizar um zoneamento da bacia do rio Moju, Pará, evidenciando a interconexão existente entre os principais usos e cobertura da terra e os usos da água, demonstrando assim, as pressões sobre os recursos naturais que a bacia sofre no atual contexto desenvolvimentista da região.

\section{MATERIAL E MÉTODOS}

\section{1. Área de estudo}

A bacia hidrográfica do rio Moju $\left(15.661,695 \mathrm{~km}^{2}\right)$ se localiza a nordeste do Estado do Pará (Figura 1). No contexto da Política Estadual de Recursos Hídricos (Lei 6.381/2001) inserem-se na Região Hidrográfica Costa Atlântica Nordeste, conforme Resolução no 04/2008 do Conselho Estadual de Recursos Hídricos. Essa Região Hidrográfica ocupa 10,1\% da área do Estado (Pará, 2012). É formada pelos municípios de Moju (integralmente), Breu Branco, Goianésia do Pará e Jacundá (Figura 1). É de $5^{\mathrm{a}}$ ordem (segundo Strahler) com forte orientação N-S e secundariamente E-W. Sua forma alongada favorece a ação da drenagem sobre as formas de relevo, sendo compartimentada em: Baixo Moju (BMj), Médio Moju (MMj) e Alto Moju (AMj) (Figura 1) (Ferreira et al., 2016). A região do AMj é a mais densamente ocupada e recortada por vias de acesso com ligação com o município de Tucuruí. Na bacia do rio Moju, é considerado um universo de população superior a cem mil pessoas, já que esta abrange integralmente o município de Moju, parte dos municípios de Goianésia, Breu Branco e Jacundá - contemplando a sede municipal deste último no interior da bacia.

\subsection{Zoneamento da bacia com as áreas de maior pressão sobre os recursos naturais}

No processo de construção do zoneamento, buscou-se classificar por sub-bacia a pressão causada por demandas de água e de solo. Para tanto, foram atribuídos níveis de pressão (baixo, intermediário e alto) de acordo com a intensidade dos usos dos recursos naturais.

Com intuito de verificar as demandas por água (superficial e subterrânea) foram utilizados os dados de outorgas (de direito e prévias) de recursos hídricos da Secretaria Estadual de Meio Ambiente e Sustentabilidade do Estado do Pará (SEMAS- PA), dados dos poços cadastrados no Sistema de Informações de Águas Subterrâneas (SIAGAS) do Serviço Geológico do Brasil (CPRM, 2016) com status "bombeando", e o consumo referente ao abastecimento humano levantado junto ao Sistema Nacional de Informações Sobre Saneamento (SNIS, 2014), utilizando o último ano disponibilizado no sistema (2014). Entretanto, o município de Goianésia do Pará foi o único que não apresentou informações para este ano na plataforma do SNIS, sendo necessário recorrer à Pesquisa Nacional de Saneamento Básico de 2008 do Instituto Brasileiro de Geografia e Estatística (IBGE, 2008) para obter informações deste município.

As demandas por terra foram verificadas através de dados digitais de uso e cobertura da terra oriundos do Projeto TerraClass de Mapeamento de Unidades de Uso do Solo 2014 (INPE, et al., 2014), onde foram consideradas dez classes: Agricultura anual (áreas extensas com predomínio de culturas de ciclos anuais); Mineração (área de extração mineral); Reflorestamento (áreas que após o corte raso foram reflorestadas com espécie exóticas com finalidade comercial); Área Urbana (manchas urbanas decorrentes da concentração populacional); Mosaico de Ocupações (área representada por uma associação de diversas modalidades de usos da terra); Desflorestamento/2014; Área não observada (áreas que tiveram

Rev. Ambient. Água vol. 12 n. 4 Taubaté - Jul. / Aug. 2017 
sua interpretação impossibilitada pela presença de nuvens ou sombra de nuvens); Não Floresta (áreas ocupadas por fitofisionomias não florestais, como campos e campinaranas); Vegetação Secundária (estrato arbóreo representado por floresta plantada (reflorestamento comercial), com cultura permanente; Estrato arbustivo representado por vegetação natural ou seminatural); Hidrografia; Outros (áreas que não se enquadravam nas chaves de classificação, como: praias fluviais, bancos de areia, entre outros) e Pastagem (áreas de pastagem em processo produtivo).

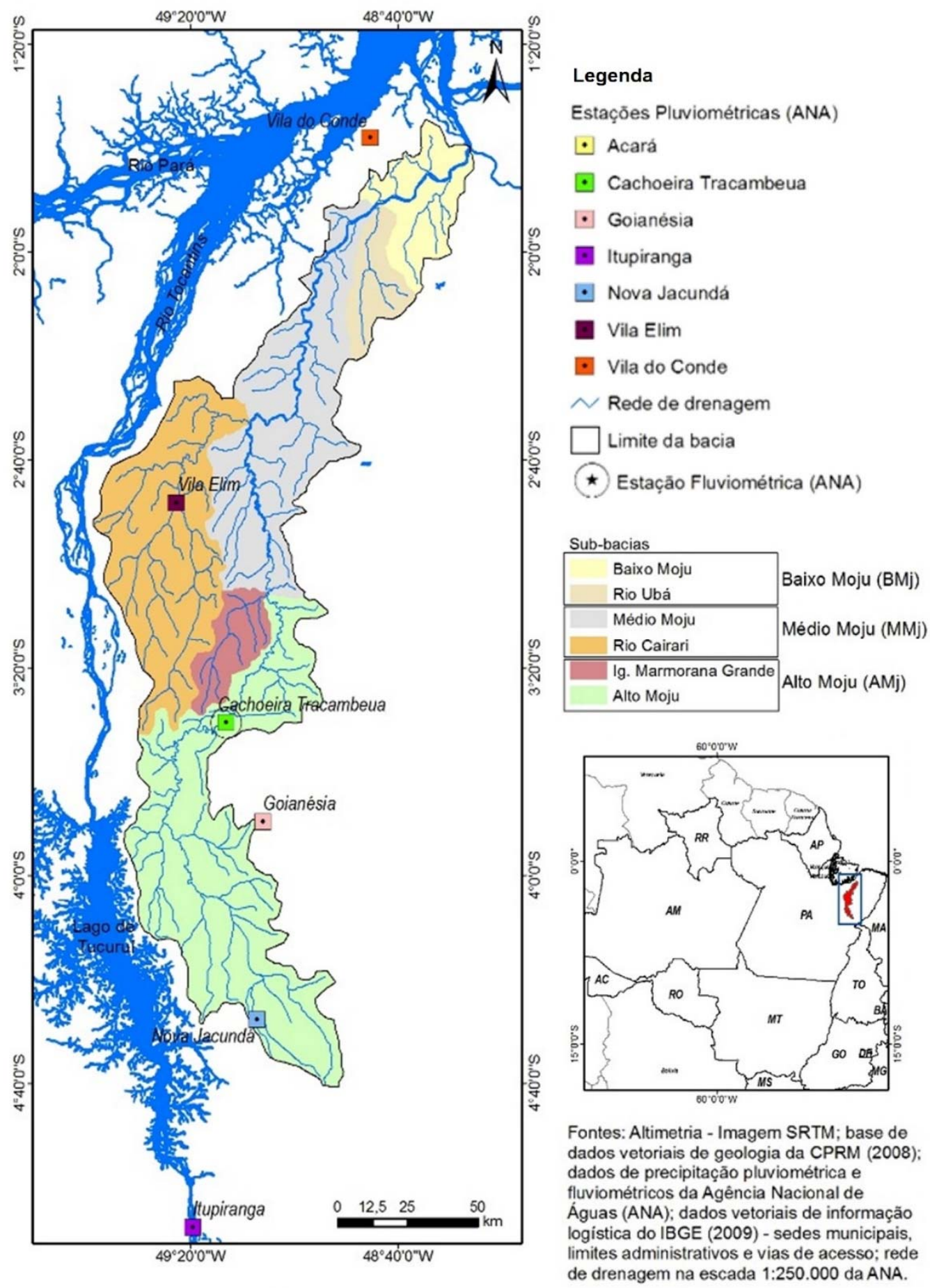

Figura 1. Localização da área de estudo. 
Foram seguidas as seguintes etapas: primeiramente foi elaborado um mapa de uso e cobertura da terra da bacia do rio Moju considerando as classes já definidas e mapeadas pelo TerraClass; em seguida foram plotados, de acordo com sua localização geográfica, os pontos de usos superficiais e subterrâneos de água; depois foi realizada uma análise de quais classes de usos da terra tem maior demanda por água, bem como foi considerado o consumo referente ao abastecimento humano (SNIS e IBGE) como critério de pressão; e, por fim foi feita uma representação gráfica onde foi possível evidenciar os níveis de pressão sobre os recursos naturais nas sub-bacias que compõe a bacia do rio Moju.

Os softwares empregados na atividade relacionada ao geoprocessamento foram: ArcGis 10 - na elaboração do mapa temático; e software V-LATE 2.0 na análise quantitativa da estrutura da paisagem. Os resultados obtidos nessa análise foram calculados para o ano base de 2014. Entretanto, este é apenas um ano de referência, uma vez que se utilizaram para alguns dados, valores em anos anteriores e posteriores. Isso foi necessário devido às limitações existentes, principalmente em relação à atualização temporal de determinadas informações.

\section{RESULTADOS E DISCUSSÃO}

\subsection{Avaliação de uso - outorgas}

A Tabela 1 indica a presença de grandes empreendimentos com destaque para as madeireiras e as agroindústrias do dendê. Em relação à finalidade do uso da água, a maioria dos usos outorgados diz respeito ao abastecimento industrial. Entretanto, essa relação de empreendimentos outorgados não reflete a realidade do uso da água da bacia, haja vista que a região possui muitos empreendimentos, e que a maior parte atua na irregularidade. Como exemplo, podemos citar o caso dos empreendimentos aquícolas que apesar do registro no censo do IBGE (2010) demonstrar a existência da aquicultura em todos os municípios componentes da bacia, estes ainda não aparecem na relação de empreendimentos outorgados, nem mesmo com outorga prévia. Além destes, somente duas empresas da produção agroindustrial do dendê possuem outorga, sendo que a bacia abriga quatro empreendimentos dessa natureza.

De acordo com outorgas deferidas para a bacia do rio Moju, realizou-se um quantitativo com o número de outorgas por empreendimento e por município, além da verificação de sua tipologia de uso (sendo registrados apenas dois tipos: captação subterrânea e superficial) e o número de pontos outorgados. Foi possível verificar que o número (26) de captação subterrânea prevalece em relação ao número (3) captação superficial e que não há registro de outra tipologia de outorga para a bacia, como por exemplo, a outorga para diluição de efluentes (Tabela 1).

Verificou-se também que Moju foi o município que mais requereu outorga de uso de recursos hídricos e que os empreendimentos que mais possuem outorga, 15 dos 29 existentes na bacia, são os da agroindústria da dendeicultura e da produção do óleo de palma. A ausência de outorgas associadas ao lançamento de efluentes é um fator que merece atenção, uma vez que o efluente líquido na saída do processo de extração do óleo de palma apresenta características físico-químicas que devem ser aferidas junto aos padrões recomendados pelo Conselho Nacional do Meio Ambiente (Furlan Junior, 2006).

Somente as outorgas de direitos dispunham de informações quanto a sua vazão total diária $\left(\mathrm{m}^{3} /\right.$ dia) outorgada. As vazões previstas para as outorgas prévias não estavam disponíveis na plataforma de informações da SEMAS-Pará. Com base nisso, foram calculadas para as outorgas de direito, as suas respectivas vazões totais anuais $\left(\mathrm{m}^{3} / \mathrm{ano}\right)$, levando em consideração o ano comercial composto por 360 dias (Tabela 2).

Rev. Ambient. Água vol. 12 n. 4 Taubaté - Jul. / Aug. 2017 
Tabela 1. Relação dos empreendimentos outorgados e os usos da água na bacia do rio Moju, Pará, e quantitativo das outorgas deferidas por tipologia de usos e por município na bacia do rio Moju- Pará (Ref. - Empreendimento; OD - Outorga de direito; OP - Outorga prévia; AI - Abastecimento industrial; AH - Abastecimento humano; AM - Abastecimento múltiplo; AIH - Abastecimento industrial e humano).

\begin{tabular}{llcccll}
\hline Ref. & \multicolumn{1}{c}{ Segmento } & Uso da água & $\begin{array}{c}\text { Situação da } \\
\text { outorga }\end{array}$ & $\begin{array}{c}\mathrm{N}^{\circ} \text { de } \\
\text { outorgas }\end{array}$ & Tipologia & Município \\
\hline A & Madeireira & AI & OD & 1 & Subterrânea & Moju \\
B & Madeireira & AI & OD & 1 & Subterrânea & Moju \\
C & Madeireira & AI & OD & 2 & Subterrânea & Moju \\
D & Agroindústria & AI & OD & 4 & Subterrânea & Moju \\
E & Agroindústria & AI & OP & 2 & Subterrânea & Moju \\
E $\quad$ Comércio de & combustível & AH & OD & 9 & Subterrânea & Moju \\
F & Órgão público & AH & OD & 1 & Subterrânea & Moju \\
G & Fazenda agroecológica & AM & OP & 1 & Subterrânea & Moju \\
H & Mineração & AIH & OP & 2 & Superficial & Moju \\
I & Órgão público & AH & OP & 1 & Subterrânea & Moju \\
J & Órgão público & AH & OD & 1 & Superficial & Moju \\
K & Frigorífico & AI & OP & 3 & Subterrânea & Goianésia do Pará \\
L & Frigorífico & AI & OP & 1 & Subterrânea & Jacundá \\
\hline Total de outorgas & & & $\mathbf{2 9}$ & & \\
\hline
\end{tabular}

Fonte: Pará (2016).

Tabela 2. Vazão total outorgada na bacia do rio Moju, Pará.

\begin{tabular}{cccccc}
\hline Empreendimento & $\begin{array}{c}\text { Situação de } \\
\text { outorga }\end{array}$ & Município & Tipologia & $\begin{array}{c}\text { Vazão total diária } \\
\left(\mathrm{m}^{3} / \text { dia }\right)\end{array}$ & $\begin{array}{c}\text { Vazão total anual } \\
\left(\mathrm{m}^{3} / \text { ano }\right)\end{array}$ \\
\hline A & Em vigor & Moju & Subterrânea & 14 & 5040 \\
B & Em vigor & Moju & Subterrânea & 24,57 & 8845,2 \\
C & Em vigor & Moju & Subterrânea & 56 & 20160 \\
D & Em vigor & Moju & Subterrânea & 434,6 & 156456 \\
E & Em vigor & Moju & Subterrânea & 2548,49 & 917456,4 \\
F & Em vigor & Moju & Subterrânea & 40 & 14400 \\
J & Em vigor & Moju & Superficial & 14,4 & 5184 \\
L & Em vigor & Jacundá & Subterrânea & 290 & 104400 \\
\hline TOTAL & & & & $\mathbf{3 . 4 2 2 , 0 6}$ & $\mathbf{1 . 2 3 1 . 9 4 1 , 6}$ \\
\hline
\end{tabular}

Fonte: Pará (2016).

A agroindústria apresentou as maiores vazões totais diárias e, por consequência, anuais. Alves et al. (2013) afirmam que devido à grande disponibilidade de água na região, não há um sistema de controle ou reciclagem durante a fase industrial da produção do óleo de palma, em que ocorre o maior consumo. Esses mesmos autores verificaram que apenas 1 das 4 empresas 
participantes de sua pesquisa possuia hidrômetro para verificação da quantidade de água utilizada na produção, sendo que o valor obtido foi de $6,02 \mathrm{~m}^{3} / a ́ g u a$ por tonelada de óleo produzido, superando o valor proposto por May et al. (2005) e Tan et al. (2007) de 4,8 m³água por tonelada de óleo produzido.

\subsection{Potencial de uso - águas subterrâneas}

De acordo com as informações disponibilizadas pela base de dados do SIAGAS, a bacia do rio Moju conta com 126 registros de poços. Destes, 71 estão nos limites do município de Moju, 23 em Jacundá, 16 em Goianésia do Pará e 16 em Breu Branco. Entretanto, verifica-se que há muitos poços que estão inativos, além da falta de informação sobre a situação de alguns poços em Moju e Jacundá, percebidos pela presença de células vazias (Tabela 3).

Tabela 3. Status dos poços registradas na bacia do rio Moju, Pará.

\begin{tabular}{lcccccc}
\hline Município & $\begin{array}{c}(\%) \\
\text { Bombeando }\end{array}$ & $\begin{array}{c}(\%) \\
\text { Colmatado/ } \\
\text { obstruído }\end{array}$ & $\begin{array}{c}(\%) \\
\text { Equipado }\end{array}$ & $\begin{array}{c}\text { Fechado/Parado/ } \\
\text { Abandonado }\end{array}$ & $\begin{array}{c}\text { (\%) } \\
\text { Não instalado }\end{array}$ & $\begin{array}{c}\text { (\%) } \\
\text { Células vazias }\end{array}$ \\
\hline Moju & 33,8 & 1,4 & 56,3 & 1,4 & 4,2 & 2,8 \\
Breu Branco & 37,5 & - & 50 & 12,5 & - & - \\
Jacundá & 26,1 & 8,7 & 47,8 & 8,7 & - & 4,3 \\
Goianésia do Pará & 62,5 & - & 37,5 & - & - & - \\
\hline
\end{tabular}

Fonte: CPRM (2016).

A existência de poços inativos seja por abandono, obstrução, dentre outros motivos, onde não ocorre o correto fechamento através do tamponamento com material argiloso se torna um fator preocupante, pois aumenta o risco de contaminação dos aquíferos. Para CPRM (Jorge et al., 2013), uma maneira efetiva de se proteger a qualidade da água subterrânea é a utilização de mapas de vulnerabilidade dos aquíferos, os quais devem subsidiar planos de desenvolvimento e guia de atividades humanas para minimizar os impactos na qualidade da água.

As profundidades finais dos poços ao longo da bacia variaram significativamente. Em Moju, a menor foi 18 e a maior $125 \mathrm{~m}$; Breu Branco, 36 e $90 \mathrm{~m}$; Jacundá, 55 e $200 \mathrm{~m}$ e, Goianésia, 30 e $180 \mathrm{~m}$. Esta é uma das características que podem estar relacionadas à qualidade da água. Entende-se que a profundidade pode reduzir a possibilidade de contaminação por substâncias que possuem baixa mobilidade no solo (Cappi et al., 2012).

No que se refere ao tipo de aquífero quanto a sua característica hidráulica, os municípios de Moju, Breu Branco e Goianésia do Pará apresentaram um maior percentual de poços (50,7; 56,3 e $56,3 \%$ respectivamente) perfurados em aquífero livre. Os aquíferos livres têm a chamada recarga direta, em que o nível da água varia segundo a quantidade de chuva. São os aquíferos mais comuns e mais explorados pela população. São também os que apresentam maiores problemas de contaminação (Villar e Ribeiro, 2009). Somente Jacundá possui uma diferença mais evidente, tendo $82,6 \%$ de seus poços construídos em aquífero confinado. Os aquíferos confinados, devido às suas maiores reservas, à maior produtividade da água subterrânea e ao baixo grau de vulnerabilidade, que os torna naturalmente bem protegidos, constituem os mais importantes mananciais para a explotação da água subterrânea na região (Jorge et al., 2013). Em um aquífero confinado, a área de descarga pode ficar geograficamente distante dos locais de captação. A proteção das áreas de recarga de um aquífero é um dos principais aspectos na proteção do próprio aquífero quanto à quantidade e qualidade da água (Tucci e Cabral, 2003).

Os poços foram construídos em diversos aquíferos. Todavia, a Formação Itapecuru e Formação Barreiras concentram juntas $73,4 \%$ dos poços registrados na área da bacia. Os 
aquíferos de Formação Barreiras, Itapecuru e Pirabas estão entre os principais explotados para o abastecimento público ou particular no estado do Pará. Entretanto, de acordo com Jorge et al. (2013), a produtividade do aquífero Barreiras é de média a alta, enquanto a do Itapecuru é média a fraca tendo poços com vazão específica entre 1 e $0,13 \mathrm{~m} / \mathrm{h} / \mathrm{m}$ e a vazão entre 25 e $3,2 \mathrm{~m}^{3} / \mathrm{h}$ para rebaixamento de nível d'água de $25 \mathrm{~m}$.

No que tange aos usos das águas subterrâneas da bacia, os usos apresentados foram: abastecimento doméstico, abastecimento industrial e abastecimento múltiplo. A destinação da água mais expressiva foi o abastecimento doméstico em Moju, Breu Branco e Goianésia do Pará, com os respectivos percentuais 62; 100 e 100. Em Jacundá o abastecimento doméstico teve o mesmo percentual do abastecimento industrial $(39,1 \%)$.

\subsection{Sistema de abastecimento humano de água}

A Companhia de Saneamento do Pará - COSANPA atende atualmente a 56 municípios do Estado, o que representa $39 \%$ do total, sendo o atendimento do restante dos municípios da seguinte forma: $7,6 \%$ são atendidos pela iniciativa privada e $53,6 \%$ são gerenciadas pelas próprias administrações municipais (segundo disponibilizado pela COSANPA em 06/2015). Na bacia, o número de economias abastecidas é: Moju - 1.421; Breu Branco - 1.269; Jacundá 3.425; e Goianésia - 200. Os municípios de Moju e Breu branco possuíam Estação de Tratamento de Água-ETA para tratar o seu volume de água produzido. Jacundá realizava seu tratamento por uma simples desinfecção e Goianésia não apresentou nenhum tipo de tratamento de água (Tabela 4).

Os dados do SNIS (2014) demonstram que o consumo médio de água no país é de 162 litros por habitante ao dia. Os consumos médios per capita de água em Moju ( 92 1/hab./dia) e Jacundá (87,5 1/hab./dia) se mantiveram dentro dos limites, entre 50 e 100 1/hab./dia, sugeridos pela Organização Mundial da Saúde (OMS) para assegurar a satisfação das necessidades mais básicas e a minimização dos problemas de saúde. Somente Breu Branco excedeu esse limite com um consumo médio de 116,3 1/hab./dia. Entretanto, pode-se verificar que os índices de perdas na distribuição dos municípios de Moju e Jacundá apresentam valores maiores que os da média nacional.

Tabela 4. Abastecimento de água da bacia do rio Moju, Pará, de acordo com SNIS (2014) e IBGE (2008).

\begin{tabular}{lcccccc}
\hline Município & $\begin{array}{c}\text { Volume de } \\
\text { água produzido } \\
\left(1.000 \mathrm{~m}^{3} / \text { ano }\right)\end{array}$ & $\begin{array}{c}\text { Volume de água } \\
\text { tratada em ETAs } \\
\left(1.000 \mathrm{~m}^{3} / \mathrm{ano}\right)\end{array}$ & $\begin{array}{c}\text { Volume de água } \\
\text { consumido } \\
\left(1.000 \mathrm{~m}^{3} / \mathrm{ano}\right)\end{array}$ & $\begin{array}{c}\text { Consumo } \\
\text { médio per } \\
\text { capita de água } \\
(1 / \text { hab./dia) }\end{array}$ & $\begin{array}{c}\text { Índice de } \\
\text { perdas na } \\
\text { distribuição } \\
(\%)\end{array}$ & $\begin{array}{c}\text { Índice de } \\
\text { atendimento } \\
\text { urbano de } \\
\text { água (\%) }\end{array}$ \\
\hline Moju & 421 & 421 & 227,91 & 92 & 44,68 & 21,7 \\
Breu Branco & 260 & 260 & 170,97 & 116,3 & 30,5 & 12,6 \\
Jacundá & 805 & - & 428,08 & 87,5 & 45,61 & 27,7 \\
$\begin{array}{l}\text { Goianésia } \\
\text { do Pará }\end{array}$ & $20^{*}$ ou $7300^{* *}$ & - & - & - & - & - \\
\hline Total & $\mathbf{8 7 8 6}$ & $\mathbf{6 8 1}$ & $\mathbf{8 2 6 , 9 6}$ & $\mathbf{2 9 5 , 8}$ & $\mathbf{3 0 , 2 0}$ & $\mathbf{1 5 , 5}$ \\
\hline
\end{tabular}

Nota: " $20\left(1000 / \mathrm{m}^{3} / \mathrm{dia}\right)$ ou ${ }^{* *} 7300\left(1000 / \mathrm{m}^{3} / \mathrm{ano}\right)$, considerando um ano de 365 dias.

O índice de atendimento urbano de água foi considerado muito baixo $(<30 \%)$. Goianésia do Pará não disponibilizou tais informações. Em 2014 o índice de perdas de água na distribuição, de acordo com os dados do SNIS, distribui-se segundo os municípios brasileiros nas seguintes quantidades para cada faixa analisada: 1.511 municípios $(29,9 \%)$ com índices menores que 20,0\% (melhores resultados); 1.240 municípios (24,6\%) com índices na faixa de 
20,0 a 30,0\%; 911 municípios (18,0\%) na faixa de 30,1 a 40,0\%; e 1.385 municípios (27,4\%) com índices acima de 40,0\% (pior faixa). Portanto, observa-se que os municípios que constituem a bacia do rio Moju estão entre os municípios brasileiros que apresentam as piores faixas de perdas de águas na distribuição.

\subsection{Zoneamento das áreas de maior pressão na bacia do rio Moju}

Analisando por sub-bacia, o Baixo Moju (BMj) possui uma área de aproximadamente $1.901 \mathrm{~km}^{2}$, sendo que, deste total, $42 \%$ corresponde a floresta e $35 \%$ à vegetação secundária (Figura 2). O desmatamento para o ano de 2014 cresceu pouco, menos de $1 \mathrm{~km}^{2}$. Ao norte da bacia do rio Cairari $(\mathrm{MMj})$ há uma extensa área de vegetação secundária que pode trazer benefícios a bacia, uma vez que áreas com concentração de pequenos produtores rurais tendem a abrigar grandes extensões de vegetação secundária devido aos ciclos repetitivos de corte e queima nas áreas de agricultura tradicional que influem positivamente na formação de capoeiras (Perz e Skole, 2003). Nessas paisagens, florestas em diversos estágios de degradação e regeneração trazem consideráveis benefícios como a proteção da biodiversidade e a manutenção dos mais diversos serviços ambientais (Vieira, 2012).

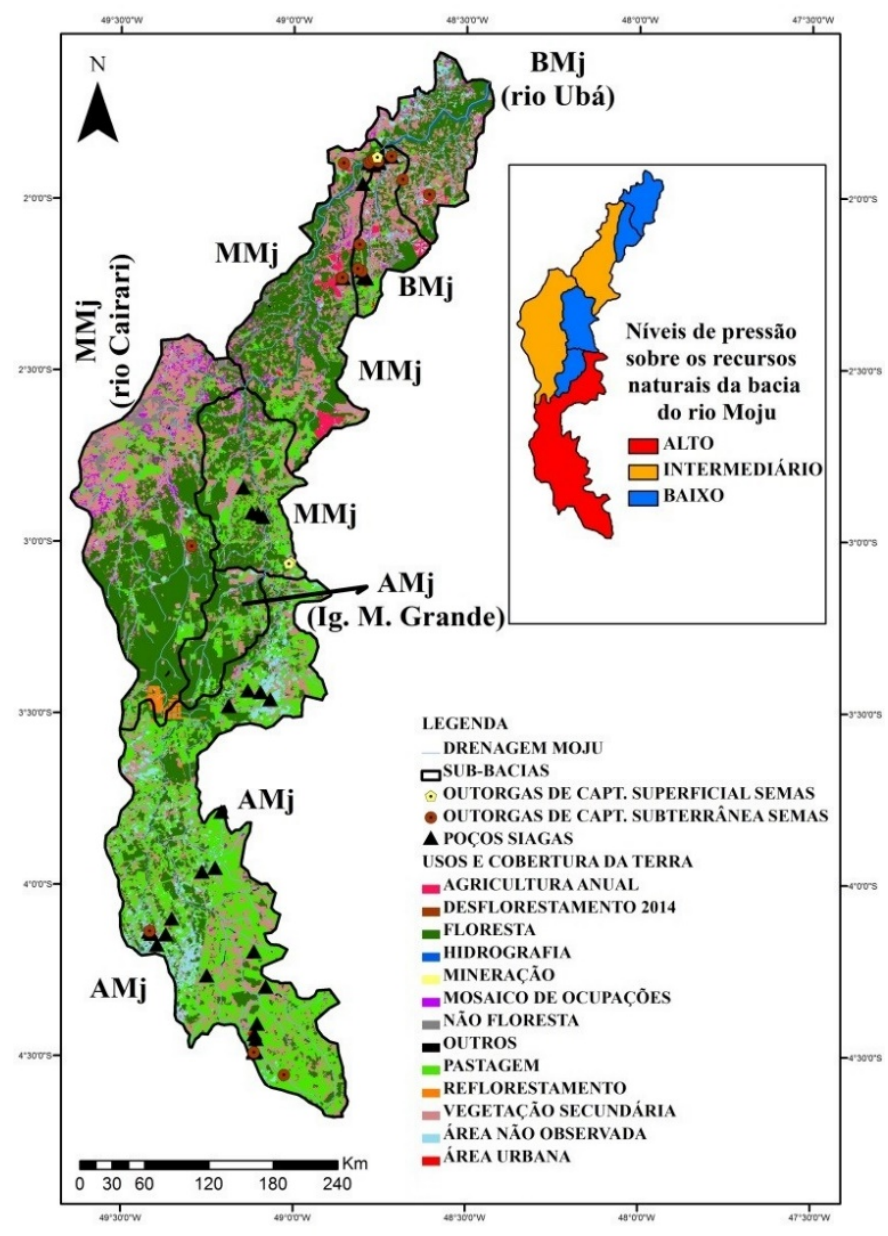

Figura 2. Zoneamento das áreas de maior pressão sobre os recursos naturais da bacia do rio Moju, Pará.

Pastagens e agriculturas anuais são presentes e marcantes, principalmente na área de influência do rio Ubá, localizado ao norte do município de Moju, um dos principais afluentes do rio Moju pela margem direita. O rio Ubá é de suma importância para as comunidades rurais, 
oferecendo subsídios agrícolas, pesqueiros, entre outros. Grande parte da bacia hidrográfica é também ocupada por explorações madeireiras e plantio de dendê. No rio Ubá, o processo de ocupação aliado à exploração madeireira seletiva, atividade agrícola e a pecuária provocaram alterações drásticas nas áreas de florestas primárias e secundárias, comprometendo as matas ciliares, as nascentes e a qualidade da água (Miranda et al., 2016).

Quanto aos usos da água, o BMj não tem um grande número de outorgas, sendo todas subterrâneas. Verificou-se a presença de 7 outorgas SEMAS e 6 poços SIAGAS. No que se refere à distribuição do uso da água por uso e cobertura da terra, na área de pastagem foram encontrados 6 poços, na vegetação secundária foram 5, e 1 poço na área de floresta. Em se tratando do consumo humano, a rede de distribuição só atende a sede municipal, onde se localiza o município de Moju. É constatado um grande percentual de perdas na distribuição $(44,68 \%)$ e um pequeno índice de atendimento urbano $(21,7 \%)$ (Tabela 4$)$.

O Médio Moju (MMj) tem 7453,64 km², sendo a floresta a classe de uso e cobertura da terra que apresenta maior área (aproximadamente $3447 \mathrm{~km}^{2}$ ). Contudo, nota-se que essa subbacia é uma área bastante antropizada com fortes atividades econômicas para a região como: agricultura, mineração e pecuária. O desflorestamento de 2014 chegou perto dos $19 \mathrm{~km}^{2}$ e o reflorestamento com espécies exóticas foi de quase $40 \mathrm{~km}^{2}$. Possui o mais expressivo afluente (localizado a margem esquerda) do rio Moju- o rio Cairari. No MMj são 36 pontos de captação de água, sendo 3 de captação superficial e os pontos restantes são de captação subterrânea. A classe de uso e cobertura da terra que mais demanda por água é a área urbana com 11 pontos. A sub-bacia que mais sofre pressão sobre o uso de seus recursos naturais é a do Alto Moju $(\mathrm{AMj})$, tendo a maior parte de seu território, $45 \%$, convertido em pastagem.

$\mathrm{O}$ AMj tem $6307 \mathrm{~km}^{2}$ e, ao longo de sua extensão, percebe-se a forte influência da agropecuária, sendo a classe pastagem a que mais possui pontos de captação de água (14 de um total de 25 pontos, sendo todos subterrâneos). É constituído pelos municípios de Breu Branco, Goianésia do Pará e Jacundá. Esses municípios fazem parte da Região de Integração Lago de Tucuruí, e, portanto, sofrem forte influência do processo de ocupação registrado através da implantação da usina hidrelétrica de Tucuruí. O desflorestamento para o ano de 2014 ficou em torno dos $10 \mathrm{~km}^{2}$ e o reflorestamento ficou próximo aos $27 \mathrm{~km}^{2}$. Atividades como mineração e agricultura anual possuem menos de $1 \mathrm{~km}^{2}$ de área cada, e a área urbana, representada pela sede municipal de Jacundá, possui cerca de $16 \mathrm{~km}^{2}$. Nessa sub-bacia está inserido o igarapé Mamorana Grande, que atua como a principal drenagem contribuinte de recarga desta área. A informação do consumo humano desta sub-bacia é prejudicada pela ausência de resposta ao SNIS por parte do município de Goianésia, entretanto, destaca-se o alto índice de perdas na distribuição que chega a 45,61 \%, e o ínfimo índice, inferior a 30\%, de atendimento urbano (Tabela 4).

O zoneamento aponta que $73,7 \%$ de área total da bacia hidrográfica do rio Moju se encontra com níveis de pressão sobre os seus recursos naturais variando entre alto a intermediário. Fato este que pode ser fortemente influenciado pelo Novo Código Florestal que, de acordo com Almeida e Vieira (2014), remete a uma situação crítica quanto à manutenção das matas ciliares na Amazônia por dar legitimidade às perdas de biodiversidade e de recursos hídricos a partir das mudanças estabelecidas nas regras de recomposição. Isso gera um fator de alerta sobre esses recursos naturais aqui analisados, tendo em vista que a cadeia do dendê ainda não está totalmente consolidada no nordeste paraense. $\mathrm{O}$ aumento de área plantada de dendezeiros poderá resultar em alterações nos ecossistemas da região, e é preciso aumentar o comando e controle no polo de produção de biodiesel para sustar o perigo de expansão do dendezeiro em APPs (Homma e Vieira, 2012).

Estudos (Lebid e Henkes, 2015; Lees et al., 2015; Almeida e Vieira, 2014; Nahum e Santos, 2013; Homma e Vieira, 2012) apontam que as principais alterações causadas pelo uso da terra no nordeste paraense ao longo dos últimos 10 anos foram: perda de vegetação natural 
nas Áreas de preservação permanente (APPs) e Reservas Legais (RLs); perda de biodiversidade faunística e de floresta; áreas naturais alteradas por atividades econômicas como a pecuária e plantio de dendê; contaminação de corpos hídricos; além dos impactos sociais e econômicos para as populações locais.

As transformações ambientais e sociais estão passíveis de grandes efeitos nocivos demandando, portanto, um gerenciamento ambiental com fortes poderes de articulação entre planejamento territorial, gestão hídrica e o setor econômico desta região.

\section{CONCLUSÃO}

Os resultados demonstraram que, para a bacia do rio Moju, a maior parcela de usos outorgados tem finalidade industrial, sendo a captação subterrânea massivamente superior a superficial, onde o principal outorgante é a agroindústria da cadeia produtiva do dendê. Percebe-se que não há controle de efluentes na bacia, uma vez que não existe outorga para sua diluição. Além disso, ainda há muitos empreendimentos que atuam na irregularidade sem a outorga de recursos hídricos. Em se tratando do abastecimento humano, destaca-se o ínfimo número de habitantes atendidos pela distribuição de água, grandes taxas de desperdício na distribuição e, existência de ETA somente em Moju e Breu Branco.

O zoneamento evidenciou que o Alto Moju é a sub-bacia que mais sofre pressão sobre os seus recursos naturais, onde $45 \%$ de seu território foi convertido em pastagem, além de possuir uma demanda expressiva por recursos hídricos. Nota-se que a bacia do rio Moju, como um todo, ainda possui a maior parte de seu território com cobertura florestal, entretanto a pastagem e a vegetação secundária são classes que sobressaem no zoneamento. A pastagem se apresenta como a classe de uso e cobertura da terra que mais demanda por água, destacando-se a captação subterrânea.

Em geral, percebe-se que o maior desafio para a bacia hidrográfica do rio Moju está em relação ao gerenciamento dos recursos hídricos que deve estar atrelado a uma competente gestão de uso do solo, para que haja um atendimento adequado à demanda do abastecimento humano e do setor produtivo, cada vez mais crescente nesta região altamente marcada por incentivos governamentais afim da consolidação da cadeia produtiva do dendê. Faz-se necessário a avaliação e monitoramento temporal e espacial em níveis quali-quantitativos não só dos recursos hídricos da bacia, mas também da ocupação territorial, analisando a dimensão social, ambiental e de gestão dos recursos naturais de forma integrada e interdisciplinar, gerando resoluções de problemas e conflitos pelos recursos naturais que irão influenciar fortemente o alcance do desenvolvimento regional sustentável.

\section{REFERÊNCIAS}

AGÊNCIA NACIONAL DE ÁGUAS - ANA (Brasil). Atlas Brasil: abastecimento urbano de água: resultados por estado. Brasília, 2010. 72p.

ALMEIDA, A. S. de; VIEIRA, I. C. G. Conflitos no uso da terra em Áreas de Preservação Permanente em um polo de produção de biodiesel no Estado do Pará. Revista Ambiente \& Água, v. 9, p. 476-487, 2014. http://dx.doi.org/10.4136/ambi-agua.1410

ALVES, S. A. O.; AMARAL, W. A. N.; HORBACH, M. A.; ANTIQUEIRA, L. M. O. R.; DIAS, I. F. S. Indicadores de sustentabilidade da agroindústria do dendê no estado do Pará. Revista Energia na Agricultura, v. 28, n. 4, p. 240-246, 2013. http://dx.doi.org/10.17224/EnergAgric.2013v28n4p240-246

Rev. Ambient. Água vol. 12 n. 4 Taubaté - Jul. / Aug. 2017 
BECKER, B. Amazônia: geopolítica na virada do III milênio. Rio de Janeiro: Garamond, 2009. $168 \mathrm{p}$.

BORDALO, C.; COSTA, F. Uma análise das primeiras experiências de gestão em bacias hidrográficas na Amazônia. Entre-Lugar, ano 3, n. 5, p 103-115, 2012.

BORDAlO, C. A. L.; FERREIRA, C. A. C.; SILVA, F. A. O.; MORAES, R. C. Os desafios da gestão das águas nas metrópoles da Amazônia: uma análise do modelo de gestão pública dos sistemas de abastecimento de água na região metropolitana de Belém - PA. Revista Geonorte, Edição Especial, v.3, n.4, p. 1181-1193, 2012.

BRASIL. Casa Civil. Subchefia para Assuntos Jurídicos. Lei n 9.433, de 08 de janeiro de 1997. Diário Oficial [da] União, 09 jan. 1997.

CAPPI, N.; AYACH, L. R.; SANTOS, T. M. B. S.; GUIMARÃES, S. T. L. Qualidade da água e fatores de contaminação de poços rasos na área urbana de Anastácio (MS). Geografia Ensino \& Pesquisa, v. 16, n. 3, 2012. http://dx.doi.org/10.5902/223649947581

COMPANHIA DE PESQUISA E RECURSOS MINERAIS - CPRM. Sistema de Informações de Águas Subterrâneas - SIAGAS. Disponível em: http://siagasweb.cprm.gov.br/layout/apresentacao.php. Acesso em: 20 mar. 2017.

FERREIRA, S. C. G.; SILVA, L. M.; LIMA, A. M. M. CORRÊA, J. A. M. A sustentabilidade hídrica da bacia hidrográfica do rio Moju a partir de indicadores de disponibilidade e demanda. In: BORDALO, A. L.; SILVA, C. N.; SILVA. E. V. (Orgs). Planejamento, conflitos e desenvolvimento sustentável em bacias hidrográficas: experiências e ações. Belém: GAPTA/UFPA, 2016. p. 601-629.

FURLAN JUNIOR, J. Dendê: manejo e uso dos subprodutos e dos resíduos. Belém: Embrapa Amazônia Ocidental, 2006. 40 p. (Embrapa Documentos, 246).

HOMMA, A. K. O.; VIEIRA, I. C. G. Colóquio sobre dendezeiro: prioridades de pesquisas econômicas, sociais e ambientais na Amazônia. Amazônia: Ciência \& Desenvolvimento, v. 8, n. 15, p. 79-90, 2012.

INSTITUTO BRASILEIRO DE GEOGRAFIA E ESTATÍSTICA - IBGE. Censo 2010. Brasília, 2010. Disponível em: http://cidades.ibge.gov.br/xtras/ Acesso em: 15 out. 2016.

INSTITUTO BRASILEIRO DE GEOGRAFIA E ESTATÍSTICA - IBGE. Pesquisa Nacional sobre Saneamento Básico (PNSB). Brasília, 2008. Disponível em: http://www.ibge.gov.br/home/estatistica/ Acesso em: 10 out. 2016.

INSTITUTO NACIONAL DE PESQUISA ESPACIAL. Centro Regional da Amazônia INPE/CRA; EMBRAPA AMAZÔNIA ORIENTAL - CPATU; EMBRAPA INFORMÁTICA AGROPECUÁRIA - CNPTIA. Projeto TerraClass. Brasília, 2014. Disponível em: http://www.inpe.br/cra/ Acesso em: 10 out. 2016

JORGE, J. X. S.; TEIXEIRA, S. G.; FONSECA, D. D. F. (Orgs.). Geodiversidade do estado do Pará. Belém: CPRM, 2013. 256 p.

LEBID, T.; HENKES, J. A. Óleo de dendê na produção de biodiesel: Um estudo de caso das vantagens e desvantagens econômica, ecológica e social da cultura desta oleaginosa para a produção de biodiesel. Revista Gestão \& Sustentabilidade Ambiental, v. 4, n. 1, p. 392- 415. 2015. http://dx.doi.org/10.19177/rgsa.v4e12015416-447 
LEES, A. C.; MOURA, N. G.; ALMEIDA, A. S.; VIEIRA, I.C.G. Poor prospects for avian biodiversity in Amazonian oil palm. PLoS ONE, v.10, n. e0122432, 2015. https://doi.org/10.1371/journal.pone.0122432

MAY, C. Y.; NGAN, M.; WENG, C. K.; BASIRON, Y. Palm diesel: an option for greenhouse gas mitigation in the energy sector. Journal of Oil Palm Research, Kuala Lumpur, v. 17, n. 1, p. 47-52, 2005.

MIRANDA, C. S. C.; ROSA, L.; GONÇALVES, N.; OLIVEIRA, F.; BONITO, J. Impactos ambientales en la microcuenca del río Parafuso, Amazonas oriental, Brasil. Gestión y ambiente, v. 19, n. 1, p. 123-140, 2016.

NAHUM, J. S.; SANTOS, C. B. Impactos socioambientais da dendeicultura em comunidades tradicionais na Amazônia paraense. ACTA Geográfica, p. 63-80, 2013.

PARÁ. Secretaria Estadual do Meio Ambiente - SEMA. Banco de dados de outorga. Belém, 2016.

PARÁ. Secretaria de Estado de Meio Ambiente - SEMA. Política de recursos hídricos do estado do Pará. Belém, 2012.

PERZ, S. G.; SKOLE, D. L. Secondary Forest Expansion in the Brazilian Amazon and the Refinement of Forest Transition Theory. Society \& Natural Resources, v.16, p.277-294, 2003. http://dx.doi.org/10.1080/08941920390178856

RODRIGUEZ, J. M. M.; SILVA, E. V.; LEAL, A. C. Planejamento ambiental de bacias hidrográficas desde a visão da geoecologia da paisagem. In. FIGUEIRÓ, A. S.; FOLETO, E. (Org.). Diálogos em geografia física. Santa Maria: Ed. da UFSM, 2011.

SISTEMA NACIONAL DE INFORMAÇÕES SOBRE SANEAMENTO. Website. 2014. Disponível em: http://www.snis.gov.br/ Acesso em: 10 nov. 2016.

SWAROWSKY, A.; DAHLGREN, R. A.; TATE, K. W.; HOPMANS, J. W.; O'GEEN, A. T. Catchment-Scale Soil Water Dynamics in a Mediterranean-Type Oak Woodland. Vadose Zone Journal, v. 10, p. 800-815, 2011. http://dx.doi.org/10.2136/vzj2010.0126

TAN, K. T.; LEE, K. T.; MOHAMED, A. R.; BHATIA, S. Palm oil: Addressing issues and towards sustainable development. Renewable and sustainable energy reviews, v. 13, n. 2, p. 420- 427, 2007. https://doi.org/10.1016/j.rser.2007.10.001

TUCCI, C. E. M.; CABRAL, J. J. S. P. Qualidade da água subterrânea. Porto Alegre: IPH/UFRGS; Recife: CT/UFPE, 2003. 53 p.

UNITED STATES. Department of Agriculture - USDA. Indonesia: Rising Global Demand Fuels Palm Oil Expansion. Commodity Inteligence Report. 2010. Disponível em: http://www.pecad.fas.usda.gov/highlights/2010/10/indonesia/ Acesso em: 16 mar. 2017.

VIEIRA, I. C. G. Florestas secundárias tropicais: ecologia e importância em paisagens antrópicas. Boletim do Museu Paraense Emílio Goeldi. Ciências Naturais, v. 7, n. 3, p. 191-194, 2012.

VILLAR, P. C.; RIBEIRO, W. C. Sociedade e gestão do risco: o aquífero Guarani em Ribeirão Preto-SP, Brasil. Revista de Geografía Norte Grande, n. 43, p. 51-64, 2009. http://dx.doi.org/10.4067/S0718-34022009000200003 
VILLELA, A. A.; JACCOUD, D.; ROSA, L. P.; FREITAS, M. V. Status and prospects of oil palm in the Brazilian Amazon. Biomass Bioenerg, v. 67, p. 270-278, 2014. https://doi.org/10.1016/j.biombioe.2014.05.005 